\title{
All-cause mortality of insulin plus dipeptidyl peptidase-4 inhibitors in persons with type 2 diabetes
}

\author{
Fu-Shun Yen ${ }^{1}$, Jen-Huai Chiang ${ }^{2,3}$, Chii-Min Hwu ${ }^{4}$, Yu-Hsin Yen ${ }^{5}$, Boniface J. Lin ${ }^{6}$, James Cheng-Chung Wei ${ }^{7^{*}}$ and \\ Chih-Cheng $\mathrm{Hsu}^{8,9,10^{*}}$
}

\begin{abstract}
Background: Dipeptidyl peptidase-4 (DPP-4) inhibitors could effectively reduce HbA $\mathrm{A}_{1 \mathrm{C}}$ and postprandial hyperglycemia and could incur only minimal danger of hypoglycemia. Patients with uncontrolled diabetes might be treated by the complementary action of insulin plus DPP-4 inhibitors. Here, we compared the all-cause mortality risk between DPP-4 inhibitor users and nonusers with underlying insulin therapy.
\end{abstract}

Methods: Using the population-based National Health Insurance Research Database of Taiwan, we conducted an 11-year retrospective cohort study. A total of 3120 patients undergoing insulin therapy for type 2 diabetes mellitus (T2DM) during 2000-2010 were enrolled. The overall incidence rates for all-cause mortality of 1560 DPP-4 inhibitor users and 1560 matched DPP-4 inhibitor nonusers were compared.

Results: No significant difference was found in the baseline demographic and clinical variables of the two groups of patients. Median follow-up period for the matched cohort was 1.67 years. All-cause mortality was observed in 93 (6.0\%) of 1560 DPP-4 inhibitor nonusers and 36 (2.3\%) of 1560 DPP-4 users. The incidence rate of mortality was 11.72 for DPP-4 inhibitor users and 38.16 per 1000 person-years for DPP-4 inhibitor nonusers. After multivariate adjustment, DPP-4 inhibitor users ran a reduced mortality risk (adjusted hazard ratio $0.32,95 \% \mathrm{Cl} 0.22-0.47 ; p<0.0001$ ) than did the nonusers.

Conclusion: Risk of all-cause mortality may be reduced when using insulin plus DPP-4 inhibitors than when using insulin plus non-DPP-4 inhibitors.

Keywords: All-cause mortality, Cohort study, Match

\section{Background}

Currently, diabetes mellitus (DM) incidence is increasing rather rapidly. Per the International Diabetes Federation, 425 million adults are currently diagnosed with diabetes globally; by 2045, this number is expected to rise to 629 million. Approximatelylin 11 adults has diabetes, and every six minutes a person dies from diabetes [1]. In addition, diabetes is a major source of the global burden of disease [2]. Therefore, new ways to prevent the occurrence

\footnotetext{
*Correspondence: wei3228@gmail.com; cch@nhri.org.tw

${ }^{7}$ Division of Allergy, Immunology and Rheumatology, Chung Shan Medical University Hospital, No. 110, Section 1, Jianguo North Road, South District, Taichung City 40201, Taiwan

${ }^{8}$ Institute of Population Health Sciences, National Health Research Institutes, No.35, Keyan Road, Zhunan Township, Miaoli County 35053, Taiwan Full list of author information is available at the end of the article
}

of diabetes must be found. Patients with DM must receive optimal treatment. Upon diagnosis of DM, most patients were found to have a $50 \%$ reduction in their insulin secretion; this percentage continues to decline for 6 years after diagnosis. Eventually, most patients require insulin treatment, either alone or together with an oral agent [3]. However, Stark et al. reported that even with insulin treatment, approximately $70 \%$ of patients with diabetes fail to reach their glycemic goal [4]. Usually, basal insulin must be administered along with other oral antidiabetic drugs (OADs). Fonseca et al. conducted a meta-analysis and concluded that the early use of insulin with OADs could notably reduce glycated hemoglobin $\mathrm{A} 1 \mathrm{C}\left(\mathrm{HbA}_{1 \mathrm{C}}\right)$ and that this approach resulted in relatively low rates of hypoglycemia

(C) The Author(s). 2019 Open Access This article is distributed under the terms of the Creative Commons Attribution 4.0 International License (http://creativecommons.org/licenses/by/4.0/), which permits unrestricted use, distribution, and 
[5]. However, the safety and outcomes of insulin combined with different OADs remained to be further investigated.

Following the ingestion of nutrients, the gastrointestinal duct secretes glucose-dependent insulinotropic peptide (GIP) as well as glucagon-like peptid-1(GLP-1), which exert a powerful effect on the secretion of insulin and glucagon from the pancreas. Subsequently, both GLP-1 and GIP are quickly degraded to inactive metabolites by dipeptidyl peptidase-4 (DPP-4). By inhibiting GLP-1and GIP degradation, inhibitors of DPP-4 can improve glycemic control. GLP-1 can decelerate gastric emptying and decrease postprandial hyperglycemia. GLP-1 reduces pancreatic alpha cell glucagon secretion in hyperglycemic states. GIP can increase glucagon secretion during hypoglycemia [6]. Because DPP-4 inhibitors effectively lower postprandial glucose levels and decrease the probability of hypoglycemia, DPP4-inhibitors could harmonize the safety and action of insulin treatment. Therefore, combined treatment using DPP-4 inhibitors plus insulin is a potentially effective treatment approach for patients with poor diabetes control.

Insulin coupled with vildagliptin has been reported to significantly decrease $\mathrm{HbA}_{1 \mathrm{C}}$ compared with insulin monotherapy and to trigger fewer and less severe hypoglycemic events [7]; however, these results were from short-term randomized control trials with no long-term clinical outcomes. Therefore, in this retrospective cohort study, we assessed the risk of all-cause mortality for a treatment regimen that combined insulin and DPP-4 inhibitors.

\section{Methods}

\section{Data source}

Implemented in 1995, the National Health Insurance program is a mandatory, single-payer program that currently covers $99 \%$ of the 23 million residents of Taiwan [8]. Data for this study were extracted from the National Health Insurance Research Database (NHIRD). The NHIRD holds information regarding inpatient claims, ambulatory claims, medical institutions, drug prescriptions, and other data. The Longitudinal Health Insurance Database 2000 (LHID2000) is a subset of the NHIRD that holds the primary insurance data, from the year 2000, of $1,000,000$ randomly sampled beneficiaries. This dataset includes data on sex, date of birth, procedures, orders, and diagnosis codes based on the International Classification of Diseases, Ninth Revision, Clinical Modifications (ICD-9-CM). For the present investigation, all patient data were derived from the LHID2000. Because all care providers' and patients' identifying information is encrypted in the LHID2000, no patient could be identified using the collected data. Thus, the usual requirement to receive consent forms from the participants was waived for this study, which was approved by The Research Ethics Committee of China Medical University and Hospital (CMUH104-REC2-115).

\section{Study population}

This retrospective cohort study used Taiwanese NHIRD administrative data from January 1, 1997, to December 31 , 2010. For the period 2000-2010, newly diagnosed type 2 patients with diabetes (T2DM; ICD-9-CM: 250.x) in the age range of 18-100 years were selected. Only those patients diagnosed with T2DM at least twice in outpatient claims or at least once in inpatient claims were included to ensure diagnostic accuracy. Each of these patients had received insulin therapy after being diagnosed with T2DM. Criteria for rejecting patients were diagnosis of type 1 diabetes $(250.1 \mathrm{x})$, rheumatic heart failure (HF, 398.91), stroke (430-438), peripheral arterial occlusive disease (443.9440-444), or HF (428) before the index date of the study.

\section{DPP-4 inhibitors}

Patients who had received DPP-4 inhibitors before or after insulin treatment were recruited. The date of concurrent use of insulin plus DPP-4 inhibitors was deemed the index date. For DPP-4 inhibitor nonusers, index dates were randomly assigned corresponding to the index date of the paired DPP-4 user. The DPP-4 inhibitors prescribed were saxagliptin, sitagliptin, vildagliptin, and linagliptin.

\section{Primary outcome and causes of death}

All-cause mortality was the primary outcome of this study. The observation period spanned from the index date and proceeded to the date of death, date of withdrawal from the NHI program, or December 31, 2010, whichever came first. We also assessed the last primary diagnosis of discharge 3 months before death to search for the causes of death [9]. Per the Standardized Definitions for End Point Events in Cardiovascular Trials [10], the causes of cardiovascular $(\mathrm{CV})$ death include the following: 1 . ischemic heart disease [coronary artery disease, 410-414, 429.2; myocardial infarction (MI), 410, 411.0, 412, and 429.79]. 2. Sudden cardiac death (cardiac arrhythmia, 427; sudden cardiac arrest, V12.53). 3. HF (398.91, 402.01, 402.11, 402.91, and 428). 4. Stroke (430-438). 5. CV procedures (668.1 and 997.1). 6. CV hemorrhage (cardiac tamponade, 423.3; aortic aneurysm and dissection, 441). 7. Other CV causes (arterial embolism and thrombosis, 444). Regarding non-CV causes of death, we assessed cancers (140-208), infection $(001-139,320,321,326,421,460-466,480-$ $487,510,513,551,567,590,599,680-686,711,730$ ), nephropathy (580-589), digestive diseases (520-579, excluding 551), respiratory diseases (518.81, 518.82, $518.85,786.09,799.1)$, accidents (800-949), and suicide (950-959). The cases for which we could not get the last main diagnosis 3 months before death were defined as undetermined causes of death. 


\section{Demographics and comorbidities}

Risk factor-related comorbidities analyzed in this study include ischemic heart disease (411-414), dyslipidemia (272, A code: A182) and hypertension (401-405, A code: A260 and A269). The conditions were deemed comorbid, if a patient was diagnosed in at least two of outpatient records or at least once in inpatient records, before the initial diagnosis of T2DM.

In our patient group, we also observed the prescription of non-DPP-4-inhibitors, non-insulin antidiabetic drugs following T2DM diagnosis, for example, biguanides (metformin, buformin), sulfonylureas (chlorpropamide, acetohexamide, glibornuride, glibenclamide, gliclazide, glipizide, gliquidone, glimepiride, tolbutamide, and tolazamide), alpha-glucosidase inhibitors and thiazolidinediones (rosiglitazone, pioglitazone).

\section{Statistical analysis}

We compared the baseline characteristics, comorbidities, and other medications between users and nonusers of
DPP-4 inhibitors. We used one-to-one propensity scores to match the age (per 5 years), sex, drugs used, comorbidities, initial year of diabetic diagnosis, and index year [11]. The propensity scores of all patients were estimated through non-parsimonious multivariate logistic regression, wherein intake of DPP-4 inhibitors and 13 clinically relevant covariates (baseline characteristics) as the dependent variable and the independent variables, respectively. Matched pairs were constructed using a nearest-neighbor algorithm, with $0.995-1.0$ as the perfect proportion [12]. Differences in the categorical and continuous variables of the two groups were analyzed through chi-square test and Student t-test, respectively; whereas a Cox proportional hazard model was employed to determine the hazard ratios (HRs) and 95\% confidence intervals (95\% CI). Survival probability was derived using log-rank tests and Kaplan-Meier estimations. $P<0.05$ was deemed significant. All analyses were performed using SAS 9.4 (SAS Institute Inc., Cary, NC).

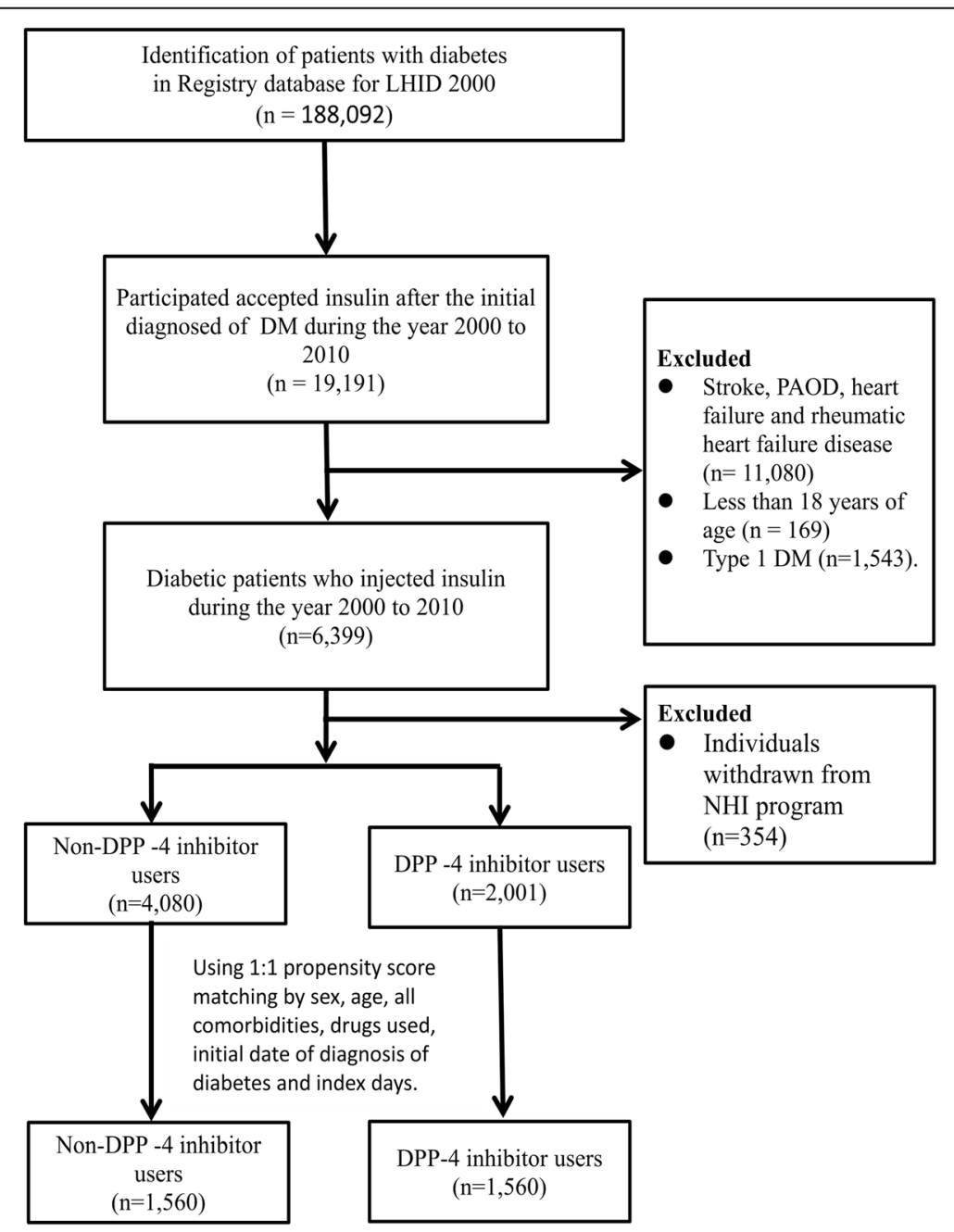

Fig. 1 Flow chart showing study design 


\section{Results}

The selection criteria described earlier yielded 3120 patients with diabetes (i.e., 1560 for each cohort) (Fig. 1). Table 1 shows their demographics. This group had more men than women. After propensity score matching, no variable differed significantly between DPP-4 inhibitor nonusers and users. The mean ages (standard deviation) of DPP-4 inhibitor nonusers and users were 49.23 (11.77) and 49.21(11) years, respectively, and the corresponding mean follow-up periods were 1.56 (1.61) and 1.97 (1.74) years.

Among DPP-4 inhibitor nonusers and users, the mortality rates were 38.16 and 11.72 per 1000 person-years, respectively, while the adjusted HR of mortality of users relative to nonusers was 0.32 (95\% CI: $0.22-0.47, P<$ 0.0001; Table 2). Moreover, the Kaplan-Meier analysis (Fig. 2) revealed that DPP-4 inhibitor users had a higher survival probability than did nonusers (log-rank test, $P<0.0001$ ).

The major identifiable causes of death of DPP-4 inhibitors users were as follows: 0 CV deaths, 31 (1.992\%) non-CV deaths, and $5(0.32 \%)$ undetermined cases. The

Table 1 Demographics and comorbidities in the study group and the control group

\begin{tabular}{|c|c|c|c|c|c|}
\hline \multirow[t]{4}{*}{ Variables } & \multicolumn{4}{|c|}{ Accepted DPP-4 inhibitors } & \multirow[t]{4}{*}{$p$-value } \\
\hline & \multirow{2}{*}{\multicolumn{2}{|c|}{$\begin{array}{l}\text { No } \\
(n=1560)\end{array}$}} & \multirow{2}{*}{\multicolumn{2}{|c|}{$\begin{array}{l}\text { Yes } \\
(n=1560)\end{array}$}} & \\
\hline & & & & & \\
\hline & $\bar{N}$ & $\%$ & $n$ & $\%$ & \\
\hline \multicolumn{5}{|l|}{$\overline{\text { Sex }}$} & \multirow[t]{3}{*}{$0.8545^{\mathrm{a}}$} \\
\hline Female & 614 & 39.36 & 609 & 39.04 & \\
\hline Male & 946 & 60.64 & 951 & 60.96 & \\
\hline \multicolumn{5}{|l|}{ Age, years } & \multirow[t]{4}{*}{$0.0919^{\mathrm{a}}$} \\
\hline 18-39years & 344 & 22.05 & 314 & 20.13 & \\
\hline 40-64 years & 1065 & 68.27 & 1119 & 71.73 & \\
\hline more than 65 years & 151 & 9.68 & 127 & 8.14 & \\
\hline Age, Mean $(S D)^{b}$ & \multicolumn{2}{|c|}{$49.23(11.77)$} & \multicolumn{2}{|c|}{$49.21(11.00)$} & $0.9573^{b}$ \\
\hline \multicolumn{6}{|l|}{ Comorbidity } \\
\hline Ischemic heart disease & 133 & 8.53 & 136 & 8.72 & $0.8483^{\mathrm{a}}$ \\
\hline Hypertension & 512 & 32.82 & 509 & 32.63 & $0.9089^{a}$ \\
\hline Dyslipidemia & 327 & 20.96 & 327 & 20.96 & $0.99^{\mathrm{a}}$ \\
\hline \multicolumn{6}{|l|}{ Other drugs } \\
\hline Biguanides & 1546 & 99.10 & 1546 & 99.10 & $0.99^{\mathrm{a}}$ \\
\hline Sulfonylureas & 1510 & 96.79 & 1494 & 95.77 & $0.13^{\mathrm{a}}$ \\
\hline Thiazolidinediones & 680 & 43.59 & 680 & 43.59 & $0.99^{a}$ \\
\hline Alpha glucosidase inhibitors & 628 & 40.26 & 666 & 42.69 & $0.1673^{\mathrm{a}}$ \\
\hline $\begin{array}{l}\text { Duration between initial date } \\
\text { of diagnosis of diabetes and } \\
\text { index days (mean, median) }\end{array}$ & \multicolumn{2}{|c|}{$2531(2530)$} & \multicolumn{2}{|c|}{2504 (2562) } & $0.5059^{b}$ \\
\hline
\end{tabular}

identifiable causes of death of nonusers were as follows: 3 (0.19\%) CV deaths, 78 (5.00\%) non-CV deaths, and $12(0.77 \%)$ undetermined cases.

\section{Discussion}

Our analysis confirmed that treatment using insulin plus DPP-4 inhibitors carried a lower risk of all-cause mortality than did treatment using insulin plus non-DPP-4 inhibitors.

Some randomized clinical trials have explored the efficacy and safety of co-administering DPP-4 inhibitors and insulin to T2DM patients. Fonseca et al. used vildagliptin [7], and Hong et al. used sitagliptin [13]; both reported significantly lower risk of hypoglycemia relative to a placebo. Lukashevich et al. [14], Kothnyetal. [15], and Kozlovskiet al. used vildagliptin [16]; Barnett et al. used saxagliptin [17]; Arnolds et al. used sitagliptin [18]; Yki-Jarvinen et al. used linagliptin [19]; all of these investigators have reported neutral effects on hypoglycemia. Visbøll et al. used sitagliptin and reported significantly higher risk of hypoglycemia [20]. These clinical trials all demonstrated significant lowering of hemoglobulin A1C $\left(\mathrm{HBA}_{1 \mathrm{C}}\right)$ and fasting plasma glucose levels, but with variable results for hypoglycemia; the reasons for such variable results regarding hypoglycemia might relate to their different patient groups and study designs. However, all these reports were from short-term and small-series clinical studies; no long-term outcomes have been noted.

Nevertheless, three recent large safety trials involving DPP-4 inhibitors have reported that these inhibitors do not raise the risks of major adverse $\mathrm{CV}$ events and mortality [21-23]. Pasquel et al. found that, for patients with T2DM, the treatment regimen of sitagliptin plus basal insulin is as safe and as effective as is the basal-bolus regimen [24]. In a post-hoc analysis, Zinman et al. investigated the CV safety of linagliptin as an insulin add-on in patients with T2DM [25] and found a neutral effect on major CV events (linagliptin 27 vs. placebo 24 events) and overall mortality ( 8 deaths in 811 patients vs. 8 deaths in 802 patients). The event rates of total mortality in this analysis might be too small to analyze. Nevertheless, our study confirmed that insulin plus DPP-4 inhibitors carries a reduced mortality risk (adjusted HR $=0.32, P<0.0001$ ). Our analysis differs from that of Zinmen et al. likely because of the differences in the characteristics of the patient populations as well as the differences in the insulin plus DPP-4 inhibitor regimens; furthermore, our study was a large series that entailed numerous incidence rates. Similarly, the differences in mortality between our study and the three afore mentioned may be attributable to all our patients receiving insulin treatment, unlike in the trials. The reduced mortality identified in this study may be attributable to the following: (1) DPP-4 inhibitors effectively decreased blood glucose level and $\mathrm{HbA}_{1 \mathrm{C}}$, with low hypoglycemia risk and 
Table 2 Risk of mortality for patients with type 2 diabetes receiving insulin treatment

\begin{tabular}{|c|c|c|c|c|c|c|c|}
\hline \multirow[t]{2}{*}{ Characteristics } & \multirow{2}{*}{$\begin{array}{l}\text { Mortality } \\
\text { no. }(n=129)\end{array}$} & \multicolumn{3}{|c|}{ Crude } & \multicolumn{3}{|c|}{ Adjusted } \\
\hline & & $\mathrm{HR}$ & $(95 \% \mathrm{Cl})$ & $P$-value & $\mathrm{HR}$ & $(95 \% \mathrm{Cl})$ & $P$-value \\
\hline \multicolumn{8}{|l|}{ DPP-4 inhibitors } \\
\hline No & 93 & 1.00 & reference & & 1.00 & reference & \\
\hline Yes & 36 & 0.33 & $(0.22-0.48)$ & $<.0001$ & 0.32 & $(0.22-0.47)$ & $<.0001$ \\
\hline \multicolumn{8}{|l|}{ Sex } \\
\hline Female & 34 & 1.00 & reference & & 1.00 & reference & \\
\hline Male & 95 & 1.86 & $(1.25-2.75)$ & 0.002 & 1.89 & $(1.28-2.8)$ & 0.0015 \\
\hline \multicolumn{8}{|l|}{ Age, years } \\
\hline 18-39years & 12 & 1.00 & reference & & 1.00 & reference & \\
\hline 40-64 years & 94 & 2.51 & $(1.38-4.58)$ & 0.0027 & 2.80 & $(1.53-5.14)$ & 0.0009 \\
\hline$\geq 65$ years & 23 & 5.37 & $(2.67-10.81)$ & $<.0001$ & 6.26 & $(3.04-12.87)$ & $<.0001$ \\
\hline \multicolumn{8}{|l|}{ Comorbidity } \\
\hline Ischemic heart disease & 17 & 1.63 & $(0.98-2.72)$ & 0.0598 & 1.71 & $(0.98-2.98)$ & 0.0601 \\
\hline Hypertension & 38 & 0.88 & $(0.6-1.28)$ & 0.4979 & 0.68 & $(0.45-1.04)$ & 0.0774 \\
\hline Dyslipidemia & 21 & 0.77 & $(0.48-1.22)$ & 0.2666 & 0.76 & $(0.46-1.23)$ & 0.2595 \\
\hline \multicolumn{8}{|l|}{ Other drugs } \\
\hline Biguanides & 128 & 1.10 & $(0.15-7.86)$ & 0.9253 & 0.91 & $(0.11-7.2)$ & 0.9263 \\
\hline Sulfonylureas & 127 & 2.18 & $(0.54-8.8)$ & 0.2752 & 2.38 & $(0.55-10.37)$ & 0.2473 \\
\hline Thiazolidinediones & 41 & 0.52 & $(0.36-0.75)$ & 0.0005 & 0.55 & $(0.38-0.81)$ & 0.0022 \\
\hline Alpha glucosidase inhibitors & 41 & 0.58 & $(0.4-0.84)$ & 0.0039 & 0.67 & $(0.46-0.98)$ & 0.0415 \\
\hline
\end{tabular}

$H R$ hazard ratio, $\mathrm{Cl}$ confidence interval

Adjusted HR: adjusted for use of DPP-4 inhibitors, age, gender, comorbidity and other drugs used in Cox proportional hazards regression

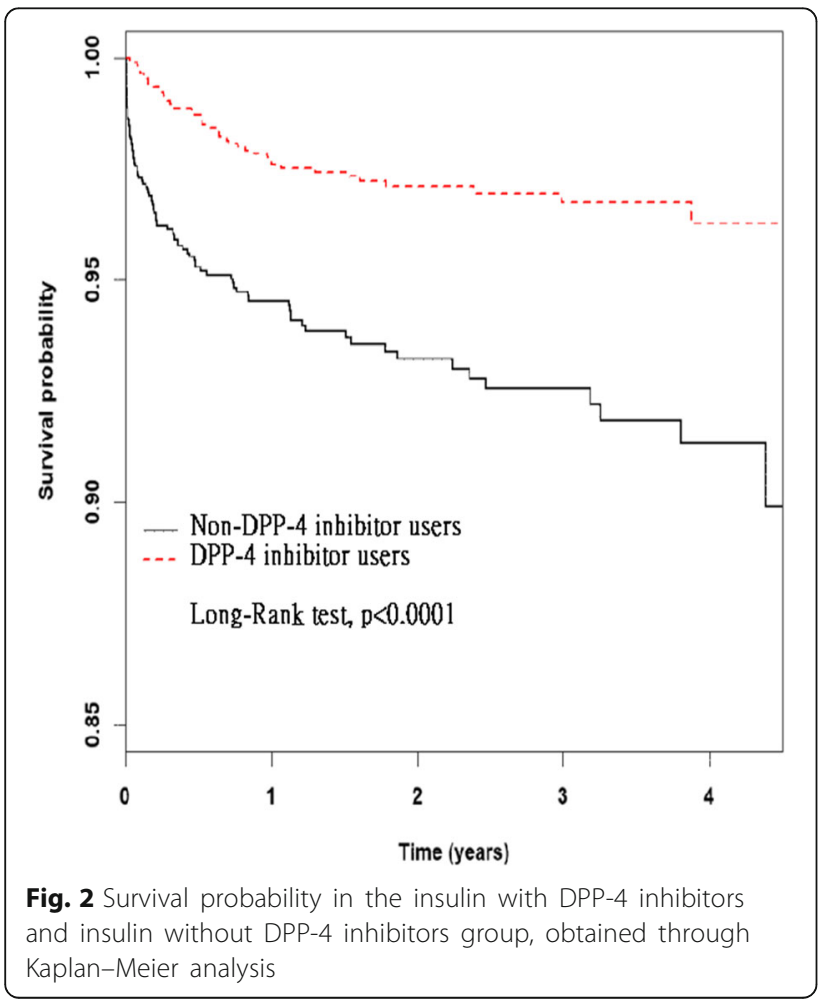

no increase in body weight [6]. (2) DPP-4 inhibitors diminished glucose excursion as well as hindered carotid atherosclerotic processes [26]. (3) The DPP-4 inhibitors increased stromal cell-derived factor 1 and recruited endothelial progenitor cells to the ischemic tissue, resulting in myocardial protection [27]. DPP-4inhibitors also enhanced the endothelial function, slowed down atherogenesis, diminished ischemia and reperfusion injury, prevented left ventricular hypertrophy and remodeling, and reduced inflammatory markers [4]. As reported in the literature, DPP-4 inhibitors could increase adiponectin levels and bring about modest reductions in lipidemia and blood pressure [28].

There were $0 \mathrm{CV}$ death in the insulin plus DPP-4 inhibitors users and only $3 \mathrm{CV}$ deaths in the non-users in our study. The low number of $\mathrm{CV}$ death might be because we had excluded the high-risk patients, such as those with heart failure, stroke or peripheral arterial occlusive disease, from the study cohort. The mean follow-up time in our study is less than 2 years, which also might lead to few cases of $\mathrm{CV}$ death.

Consistent with nationwide surveys in Taiwan [29], our study also found that male and elderly patients have relatively high mortality rates. In addition, our study showed that pioglitazone users had a relatively low mortality rate. Charbonnel et al.'s analysis of the PROactive trial demonstrated that pioglitazone plus insulin 
regimen yielded sustained improvements in glycemic control and reduced insulin doses, but it increased edema, hypoglycemia, and HF rates, with a non-significant $15 \%$ reduction in risk in the major secondary endpoint (i.e., a composite of nonfatal MI, stroke, and death) [30]. Additional rigorous analyses are essential to elucidate these results in real-world practice.

In conducting the observational studies there are several methodological issues should be addressed, such as selection bias, immortal time bias and confounding by indication. Because our database is from the National Health Insurance program, which covers 99\% of the whole residents of Taiwan, selection bias could be avoided. The first date of concurrent use of insulin and DPP-4 inhibitors was defined as the index date; so, we didn't create a follow-up period (i.e., immortal time window) within which the investigated outcomes could not happen; the chance of immortal time bias is low. The prescription of medication in the clinical practice is influenced by indications, contraindications, side effects and the preferences of patients and doctors. This might lead to the bias of "cofounding by indication"; however, we performed a 1:1 propensity score match to balance the 13 clinically relevant covariates between the users and nonusers. We believe the two study groups were comparable and the bias of cofounding by indication could be minimized as much as possible.

The present study has several strengths. First, as far as we know, this is the first study to disclose that an insulin plus DPP-4 inhibitor regimen could reduce mortality more than an insulin plus non-DPP-4 inhibitor regimen. Second, this is a large-series population-based study; the dataset is greatly representative of Taiwan's population. Third, sex, age, comorbidities, other antidiabetic drugs, and DM duration were all matched through propensity scoring to eliminate confounding factors.

However, the present study carries some limitations. Firstly, in the NHIRD, we could not obtain any data relating to the prescribed insulin dose; this is relevant because dosage might influence the analytic results. Secondly, the NHIRD does not include data on life styles, smoking habits, body weights, and economic conditions, all of which could influence mortality risks. Third, the dataset lacks biochemical blood tests, which can further express the conditions of patients under treatment. Finally, any cohort study is always subject to some inevitable biases; a randomized control trial should be conducted to affirm our results.

\section{Conclusions}

Insulin administered with DPP-4 inhibitors was able to reduce mortality and increase survival probability relative to the use of non-DPP-4 inhibitors. However, more studies are necessary to optimize the use of these DPP-4 inhibitors in real-world practice.

\begin{abstract}
Abbreviations
Cl: Confidence interval; CV: Cardiovascular; DM: Diabetes Mellitus; DPP4inhibitors: Dipeptidyl peptidase-4 inhibitors; GIP: Glucose-dependent insulinotropic peptide; GLP-1: Glucagon-like peptid-1; HbA 1 : Hemoglobin A1C; HF: Heart failure; HRs: Hazard ratios; ICD-9-CM: International Classification of Diseases, Ninth Revision, Clinical Modifications; LHID: Longitudinal Health Insurance Database; MI: Myocardial infarction; NHIRD: National Health Insurance research database; OADs: Oral antidiabetic drugs; T2DM: Type 2 diabetes mellitus
\end{abstract}

\section{Acknowledgements}

This manuscript was edited by Wallace Academic Editing.

\section{Funding}

This study was funded in part by Taiwan Ministry of Health and Welfare Clinical Trial Center (MOHW107-TDU-B-212-123004), China Medical University Hospital, Academia Sinica Stroke Biosignature Project (BM10701010021), MOST Clinical Trial Consortium for Stroke (MOST 106-2321-B-039-005-), Tseng-Lien Lin Foundation, Taichung, Taiwan, and the Katsuzo and Kiyo Aoshima Memorial Funds, Japan. The funders had no role in study design, data collection, data analysis, data interpretation, or writing of the report. The corresponding authors have full access to all data in this study and carried the final responsibility of making the decision to submit for publication.

\section{Availability of data and materials}

The dataset used in this study is from the Taiwan Ministry of Health and Welfare (MOHW), who granted us access this data. All essential data are reported in the manuscript. Any scholar seeking access to this data can apply to the MOHW: No. 488, Sec. 6, Zhongxiao E. Rd., Nangang Dist., Taipei City 115, Taiwan (R.O.C.). Phone: + 886-2-8590-6848. Email: wt.vog.whom@uwloracts.

\section{Authors' contributions}

FSY, CMH, and CCH conceived and designed the study. JCW and JHC coordinated the study and collected the data. FSY, CMH, JHC, and $\mathrm{CCH}$ participated in the interpretation of results and discussions. YHY, FSY, BJL, and $\mathrm{CMH}$ participated in the manuscript writing and critical revising. All authors agreed to all aspects of this work and ensured that questions related to the accuracy of this work were appropriately investigated and resolved.

\section{Ethics approval and consent to participate}

Because all care providers' and patients' identifying information is encrypted in the LHID2000, no patient could be identified using the collected data.

Thus, the usual requirement to receive consent forms from the participants was waived for this study, which was approved by The Research Ethics

Committee of China Medical University and Hospital (CMUH104-REC2-115).

\section{Consent for publication}

Not applicable.

\section{Competing interests}

The authors declare that they have no competing interests.

\section{Publisher's Note}

Springer Nature remains neutral with regard to jurisdictional claims in published maps and institutional affiliations.

\section{Author details}

'Dr. Yen's Clinic, No.15, Shanying Road, Gueishan District, Taoyuan City 33354, Taiwan. ${ }^{2}$ Management Office for Health Data, China Medical University Hospital, No.91, Xueshi Road, North District, Taichung City 40402, Taiwan. ${ }^{3}$ College of Medicine, China Medical University, No.91, Xueshi Road, North District, Taichung City 40402, Taiwan. ${ }^{4}$ Section of Endocrinology and Metabolism, Department of Medicine, Taipei Veterans General Hospital, No. 201, Section 2 Shi-Pai Road, Chung-Cheng Building 11F, Room536, Taipei 112, Taiwan. ${ }^{5}$ Duke-NUS Medical School, 8 College Rd, Singapore 169857, Singapore. ${ }^{6}$ Dr. Lin Clinic, No.2, Section 2, Xinsheng South Road, Da'an District, Taipei City 10650, Taiwan. 'Division of Allergy, Immunology and Rheumatology, Chung Shan Medical University Hospital, No. 110, Section 1, Jianguo North Road, South District, Taichung City 40201, Taiwan. ${ }^{8}$ Institute of Population Health Sciences, National Health Research Institutes, No.35, Keyan Road, Zhunan Township, Miaoli County 35053, Taiwan. ${ }^{9}$ Department of 
Health Services Administration, China Medical University, No.91, Xueshi Road, North District, Taichung City 40402, Taiwan. ${ }^{10}$ Department of Family Medicine, Min-Sheng General Hospital, No. 168, Jingguo Road, Taoyuan, Taiwan.

Received: 2 August 2018 Accepted: 21 December 2018

Published online: 05 January 2019

\section{References}

1. International Diabetes Federation. IDF diabetes atlas. 8th ed; 2017. https://www.idf.org/e...atlas/134-idf-diabetes-atlas-8th-edition.html. Accessed 31 May 2018

2. GBD 2015 Disease and Injury Incidence and Prevalence Collaborators. Global, regional, and national incidence, prevalence, and years lived with disability for 310 diseases and injuries, 1990-2015: a systematic analysis for the Global Burden of Disease Study 2015. Lancet. 2016;388:1545-602.

3. United Kingdom Prospective Diabetes Study Group. United Kingdom prospective diabetes study 24: a 6-year, randomized, controlled trial comparing sulfonylurea, insulin, and metformin therapy in patients with newly diagnosed type 2 diabetes that could not be controlled with diet therapy. Ann Intern Med. 1998;128:165-75.

4. Stark Casagrande S, Fradkin JE, Saydah SH, Rust KF, Cowie CC. The prevalence of meeting $\mathrm{A} 1 \mathrm{C}$, blood pressure, and $\mathrm{LDL}$ goals among people with diabetes, 1988-2010. Diabetes Care. 2013;36:2271-9.

5. Fonseca V, Gill J, Zhou R, Leahy J. An analysis of early insulin glargine added to metformin with or without sulfonylurea: impact on glycaemic control and hypoglycaemia. Diabetes Obes Metab. 2011;13:814-22.

6. Daniel JD. Enhancing incretin action for the treatment of type 2 diabetes. Diabetes Care. 2003;26:2929-40

7. Fonseca V, Schweizer A, Albrecht D, Baron MA, Chang I, Dejager S. Addition of vildagliptin to insulin improves glycaemic control in type 2 diabetes. Diabetologia. 2007;50:1148-55.

8. Cheng TM. Taiwan's new national health insurance program: genesis and experience so far. Health Aff (Millwood). 2003;22:61-76.

9. Wu CY, Chen YJ, Ho HJ, Hsu YC, Kuo KN, Wu MS, et al. Association between nucleoside analogues and risk of hepatitis B virus-related hepatocellular carcinoma recurrence following liver resection. JAMA. 2012;308:1906-14.

10. Hicks KA, James Hung HM, Mahaffey KW, Mehran R, Nissen SE, Stockbridge $\mathrm{NL}$, et al. Standardized definitions for cardiovascular and stroke end point events in Clinical Trials. Draft Definitions CDISC. 2014. https://mdepinet.org/ wp-content/uploads/S_1_6_Hicks.pdf. Accessed 31 May 2018.

11. D'Agostino RB Jr. Propensity score methods for bias reduction in the comparison of a treatment to a non-randomized control group. Stat Med. 1998;17:2265-81.

12. lezzoni LI. Risk adjustment for measuring healthcare outcomes. 2nd ed. Chicago, IL: Health Administration Press; 1997.

13. Hong ES, Khang AR, Yoon JW, Kang SM, Choi SH, Park KS, et al. Comparison between sitagliptin as add-on therapy to insulin and insulin dose-increase therapy in uncontrolled Korean type 2 diabetes: CSI study. Diabetes ObesMetab. 2012:14:795-802.

14. Lukashevich V, Schweizer A, Foley JE, Dickinson S, Groop PH, Kothny W. Efficacy of vildagliptin in combination with insulin in patients with type 2 diabetes and severe renal impairment. Vasc Health Risk Manag. 2013;9:21-8.

15. Kothny W, Foley J, Kozlovski P, Shao Q, Gallwitz B, Lukashevich V. Improved glycaemic control with vildagliptin added to insulin, with or without metformin, in patients with type 2 diabetes mellitus. Diabetes ObesMetab. 2013;15:252-7.

16. Kozlovski P, Foley J, Shao Q, Lukashevich V, Kothny W. Vildagliptin-insulin combination improves glycemic control in Asians with type 2 diabetes. World J Diabetes. 2013;4:151-6.

17. Barnett AH, Charbonnel B, Donovan M, Fleming D, Chen R. Effect of saxagliptin as add-on therapy in patients with poorly controlled type 2 diabetes on insulin alone or insulin combined with metformin. Curr Med Res Opin. 2012;28:513-23.

18. Arnolds S, Dellweg S, Clair J, Dain MP, Nauck MA, Rave K, et al. Further improvement in postprandial glucose control with addition of exenatide or sitagliptin to combination therapy with insulin glargine and metformin: a proof of concept study. Diabetes Care. 2010;33:1509-15.

19. Yki-Jarvinen H, Rosenstock J, Duran-Garcia S, Pinnetti S, Bhattacharya S, Thiemann $\mathrm{S}$, et al. Effects of adding linagliptin to basal insulin regimen for inadequately controlled type 2 diabetes: a $\geq 52$-week randomized, doubleblind study. Diabetes Care. 2013;36:3875-81.

20. Vilsbøll T, Rosenstock J, Yki-Jarvinen H, Cefalu WT, Chen Y, Luo E, et al. Efficacy and safety of sitagliptin when added to insulin therapy in patients with type 2 diabetes. Diabetes ObesMetab. 2010;12:167-77.

21. Scirica BM, Bhatt DL, Braunwald E, Steg PG, Davidson J, Hirshberg B, et al. Saxagliptin and cardiovascular outcomes in patients with type 2 diabetes mellitus. N Engl J Med. 2013;369:1317-26.

22. White WB, Cannon CP, Heller SR, Nissen SE, Bergenstal RM, Bakris GL, et al. Alogliptin after acute coronary syndrome in patients with type 2 diabetes. $N$ Engl J Med. 2013;369:1327-35.

23. Green JB, Bethel MA, Armstrong PW, BuseJ B, Engel SS, Garg J, et al. Effect of sitagliptin on cardiovascular outcomes in type 2 diabetes. N Engl J Med. 2015;373:232-42.

24. Pasquel FJ, Gianchandani R, Rubin DJ, Dungan KM, Anzola I, Gomez PC, et al. Efficacy of sitagliptin for the hospital management of general medicine and surgery patients with type 2 diabetes (Sita-Hospital): a multicentre, prospective, open-label, non-inferiority randomised trial. Lancet Diabetes Endocrinol. 2017;5:125-33.

25. Zinman B, Ahrén B, Neubacher D, Patel S, Woerle HJ, Johansen OE. Efficacy and cardiovascular safety of linagliptin as an add-on to insulin in type 2 diabetes: a pooled comprehensive post hoc analysis. Can J Diabetes. 2016;40:50-7.

26. Barbieri M, Rizzo MR, Marfella R, Boccardi V, Esposito A, Pansini A, et al. Decreased carotid atherosclerotic process by control of daily acute glucose fluctuations in diabetic patients treated by DPP-IV inhibitors. Atherosclerosis. 2013;227:224-5

27. Ussher JR, Drucker DJ. Cardiovascular biology of the incretin system. Endocr Rev. 2012;33:187-215.

28. Hibuse T, Maeda N, Kishida K, Kimura T, Minami T, Takeshita E, Hirata A, Nakagawa Y, Kashine S, Oka A, Hayashi M, Nishizawa H, Funahashi T, Shimomura I. A pilot 3-month sitagliptin treatment increases serum adiponectin level in Japanese patients with type 2 diabetes mellitus - a randomized controlled trial START-J study. Cardiovas Diabetol. 2014;13:96.

29. Li HY, Jiang YD, Chang CH, Chung CH, LinB J, Chuang LM. Mortality trends in patients with diabetes in Taiwan: a nationwide survey in 2000-2009. J Formos Med Assoc. 2012;111:645-50.

30. Charbonnel B, DeFronzo R, Davidson J, Schmitz O, Birkeland K, Pirags V, et al. Pioglitazone use in combination with insulin in the prospective pioglitazone clinical trial in macrovascular events study (PROactive19). J ClinEndocrinolMetab. 2010;95:2163-71.

Ready to submit your research? Choose BMC and benefit from:

- fast, convenient online submission

- thorough peer review by experienced researchers in your field

- rapid publication on acceptance

- support for research data, including large and complex data types

- gold Open Access which fosters wider collaboration and increased citations

- maximum visibility for your research: over $100 \mathrm{M}$ website views per year

At BMC, research is always in progress.

Learn more biomedcentral.com/submissions 